\title{
Flowering patterns change along elevational gradients and relate to life-history strategies in $\mathbf{2 9}$ herbaceous species
}

\author{
Solveig Franziska Bucher ${ }^{1}\left[\right.$ Christine Römermann ${ }^{1,2}$
}

Received: 8 July 2019 / Accepted: 25 January 2020 / Published online: 12 February 2020

(C) The Author(s) 2020

\begin{abstract}
Patterns of flowering phenology, i.e. first and last flowering day (FFD and LFD) and flowering duration (FD) govern plant pollination and reproduction. Most research has focused on FFD whereas LFD, FD and second flowering events were neglected although they are crucial events. To assess whether flowering patterns change species-specifically with changing abiotic conditions and whether these are related to leaf persistence, reproduction and pollination syndrome, we monitored flowering phenology (including also second flowering events) of 29 herbaceous species along two elevational gradients ranging from 700 to $1800 \mathrm{~m}$ a.s.l. in two consecutive years. FFD was delayed with increasing elevation. LFD followed two alternative strategies: species which ceased flowering early in the season delayed LFD with increasing elevation, species which ceased flowering late did not change LFD. FD decreased with increasing elevation in most species. The timing of flowering phenology had strong influences on the intensity of change along the elevational gradient and other stages of flowering phenology. Many species showed a second flowering event which occurred irrespective of elevation, suggesting a link to unsuccessful pollination rather than temperature. Life history strategies helped explain patterns of flowering phenology and a species' ability to track changes in abiotic conditions, e.g. evergreen species started to flower earlier than summer green species and insect-pollinated species were able to expand FD most. These findings give insight into species-specific changes in phenological patterns and thus plant performance with changing environment. They should be considered when assessing the consequences of environmental change at both the community and ecosystem level.
\end{abstract}

Keywords Altitude $\cdot$ Climate change $\cdot$ Phenology $\cdot$ Plant traits $\cdot$ Second flowering

\section{Abbreviations \\ FD Flowering duration \\ FFD First flowering day \\ LFD Last flowering day}

\section{Introduction}

Changes in patterns of flowering phenology, i.e. first and last flowering day as well as flowering duration (timespan between first and last flowering) have ecological and economic impacts on natural and agricultural landscapes (Waser and Real 1979; Rathcke and Lacey 1985; Ollerton and Lack 1998; Memmott et al. 2007; Hovenden et al. 2008). Shifts in the timing of reproduction typically influence biotic interactions such as pollination and competition (Rathcke and Lacey 1985; Visser and Both 2005; Parmesan 2007; Forrest and Miller-Rushing 2010; Wolkovich and Cleland 2011; CaraDonna et al. 2014).

Shifts in flowering phenology resulting from changing abiotic conditions have frequently been recorded and are highly species-specific (Menzel et al. 2006a; Bock et al. 2014; Bucher et al. 2018; König et al. 2018). A good understanding of species-specific changes in first flowering day (FFD) has already been achieved (Fitter et al. 1995; Bock et al. 2014; Bucher et al. 2018; König et al. 2018), yet the

2 German Centre for Integrative Biodiversity Research (iDiv) Halle-Jena-Leipzig, 04103 Leipzig, Germany 
end of flowering (last flowering day, LFD) and flowering duration (FD) are not well studied (but see Rathcke and Lacey 1985; Bock et al. 2014; Trunschke and Stöcklin 2017). However, the latter two phenological stages strongly affect pollination and reproductive success and are, therefore, crucial stages in the life-history of plant species. Prolonged flowering duration increases a plant's chance of pollination and thus likely increases plant performance (Rathcke and Lacey 1985; Menzel et al. 2006b; Bock et al. 2014; Trunschke and Stöcklin 2017). Early-flowering species are reported to be more variable in FFD than late-flowering species (Fitter et al. 1995), yet it remains unclear whether these patterns can also be observed in LFD or FD. Results from previous studies are highly ambiguous concerning FD and report reductions and prolongations with warmer climates (Miller-Rushing et al. 2007; Sherry et al. 2007; Bock et al. 2014).

Not only abiotic factors influence flowering phenology. For example, Trunschke and Stöcklin (2017) found a close relationship with pollinator abundances, with higher abundances leading to shorter FD within individuals. In a study in the Mediterranean region, Petanidou et al. (2014) demonstrated that shifts towards earlier phenology reduced pollination services and bore the risk of phenological mismatches, yet earlier flowering was associated with longer FD which might counterbalance negative effects.

In some species, second flowering events can occur towards the end of the growing season, leading to a further extension of the flowering duration, which has been widely ignored in previous research. So far, there is no evidence whether second flowering events are species-specific or can be observed more frequently under specific abiotic and biotic conditions. A lack of pollination success in the first phase might also triggers a second flowering.

There are several studies demonstrating a partial interconnection between different stages or phases of flowering phenology (hereafter referred to as events). Experimental snow removal led to an advance in FFD and an extension in FD in early-flowering species; however, there was no change in FD of later flowering species (Dunne et al. 2003). Accordingly, finding links between flowering events is important for forecasting species' behaviour under changing climatic conditions.

Few studies are available focussing on the effect of lifehistory strategies on first flowering day (Fitter and Fitter 2002; Bucher et al. 2018; König et al. 2018). Not many analysed the relation between fundamental life-history strategies such as leaf persistence (evergreen vs. summer green), pollination syndrome (insect- vs. self- or wind-pollination) or reproduction type (sexual vs. vegetative). Further, it is not known which life history strategies relate to the occurrence of a second flowering event. When comparing evergreen with summer green species, we expect evergreen species to be able to flower earlier as they are also able to photosynthesise earlier in the season. Accordingly, the development of a second flowering event may also be more likely, especially if the duration of the first flowering event is short. With regard to the pollination syndrome, we expect that the flowering phenology of insect-pollinated species shows codependencies with animals. Wind-pollinated species depend on favourable weather conditions; thus they are more susceptible to temperature than self-pollinated species. As insectpollinated species are dependent on pollinator abundance, they might show a second flowering event more often. The reproduction strategy is also likely to be correlated with changes in flowering phenology along elevational gradients. We can assume that species which mainly spread generatively are more likely to respond to changes in abiotic conditions than species, where vegetative reproduction dominates, which is more beneficial under stable conditions.

Explaining differences in species-specific patterns of flowering phenology is key to understanding and predicting changes in ecosystem functioning in response to environmental change. As data on FFD, LFD and FD measured on the same population are scarce, this study was conducted on 29 species, located along two elevational gradients, which offers the possibility to observe changes caused by differing environmental conditions (Körner 2007; Vitasse et al. 2009; Schuster et al. 2014; Bucher et al. 2018). On all populations, we monitored FFD, LFD and FD including also second flowering events in the northern limestone Alps in two consecutive years and addressed the following questions:

1. Do flowering patterns (FFD, LFD and FD) and the occurrence of a second flowering event of herbaceous species change along elevational gradients and between years or gradients? Is there a difference between species?

2. Do these changes along the elevational gradient differ between early-flowering and late-flowering species?

3. Are different events of flowering phenology interconnected, is FFD or LFD more important for observed changes in FD, and how are first and second flowering event connected?

4. Do flowering patterns differ between life-history strategies related to leaf persistence, pollination and reproduction and do they also affect the intensity of change along elevational gradients?

\section{Materials and methods}

\section{Study area and selected species}

The study was located in the vicinity of Garmisch-Partenkirchen, southern Germany. Two south-facing elevational 
gradients (hereafter referred to as "Kramer" and "Kreuzeck") were established ranging from 700 to $1800 \mathrm{~m}$ a.s.l. and 800 to $1700 \mathrm{~m}$ a.s.l., respectively. The 29 herbaceous species given in Table 1 were selected due to their occurrence along a wide elevational gradient and follow different life-history strategies in terms of leaf persistence, pollination and reproduction. The minimum and maximum temperatures of the study sites are given in Online resource 1.

\section{Flowering phenology}

Flowering phenology was monitored in 2012 and 2013 on a weekly basis. Populations of at least 20 individuals of the 29 selected species were monitored at every $100 \mathrm{~m}$ increase in elevation during the growth phase (beginning of April until beginning of November). Some elevational bands consisted of several distinct subpopulations, i.e. plants growing on up to three different meadows within the same elevational band. Altogether, we made 1496 observations in both years, which totals 965 records of plant phenology per elevational band in both years together (see Table 1). The date of FFD was recorded as the first day when an individual from a certain species and population was found to display fully developed flowers as reported in Bucher et al. (2018). LFD was determined as the day when flowers were observed for the last time in the population. The difference between these two dates was then calculated and denoted as FD. A second flowering events was also monitored which was defined as a flowering event occurring after a period of no flowers which lasted for more than 3 weeks (Online resource 2).

\section{Life history strategies}

Information on life-history strategies was taken from the BiolFlor database (Kühn et al. 2004). For each species, we extracted information on leaf persistence (evergreen or summer green), pollination syndrome (insect-, self- or wind-pollinated) and reproduction (generative or vegetative reproduction). When several entries per species and trait were given, we always selected the one which was more independent from outside conditions than the other (i.e. for pollination self $>$ wind $>$ insects, for reproduction vegetative $>$ generative). In the case of Fragaria vesca, Oxalis acetosella and Potentilla erecta we categorised the leaf persistence to be summer green based on our own observations, as the species displayed autumn senescence and completely shed their leaves during winter in the research area.

\section{Data analyses}

We used an analysis of covariance (ANCOVA) to test whether flowering phenology (FFD, LFD and FD) changed along elevational gradients and between years and whether these changes were species-specific. For these analyses we used mean FFD, LFD and FD calculated for each species within each year, gradient and elevational band as dependent variables. Elevation, the year of observation (2012 and 2013), the two elevational gradients (Kramer and Kreuzeck) and species identity, as well as the twofold interactions thereof, were used as independent variables in each model. The full models were simplified using stepwise backward selection until the minimum adequate model was found (Crawley 2012). We checked that model assumptions, i.e. homogeneity of the variances and normality of the residuals were met in all models. To see whether FFD, LFD or FD influenced the occurrence of a second flowering event, we transformed the second flowering event into presence and absence data and fitted a logistic regression with FFD, LFD and FD, respectively, as the explanatory variable. We then did the same analysis as described above for the second flowering period to see whether the second flowering event, its end and duration depend on elevation, year or gradient. In a next step, we combined both flowering events: in case of populations without a second flowering event, LFD remained consistent; for the others, we summed up the flowering duration of both flowering events.

Any reference to slope refers to the slope extracted from lines predicted by our stepwise model selection as described above, taking the flowering event, i.e. FFD, LFD and FD into consideration. To study whether the extent to which species change their flowering phenology along elevational gradients can be explained by the time of flowering (i.e. whether shifts in flowering pattern depend upon time of flowering), we first calculated the time of flowering as the mean date of the phenological event (FFD, LFD, FD) for each species on each of the two elevational gradients in each year as the independent variable. Second, we assessed the extent of phenological change by taking the slopes of the predicted lines for each species resulting from our stepwise model selection described above as a dependent variable. To take the second flowering event into account, we performed the same analysis as described above but used the last flowering day of the populations as well as the combination of the flowering duration within each population as a dependent variable and the slopes of those along the elevational gradient.

To investigate relationships between the three different phenological events, we regressed (a) FFD against LFD; (b) FFD against FD; and (c) LFD against FD. For these analyses, we included all values obtained from all the populations in our models. Again, this was done by also including a second flowering event as described above in a second step. We used ANCOVAs and included FFD, FD and LFD as well as species, gradient and year as independent variables. To see whether FFD or LFD was more important for FD, we constructed a linear regression using FD as the dependent variable and FFD as well as LFD as independent variables. 


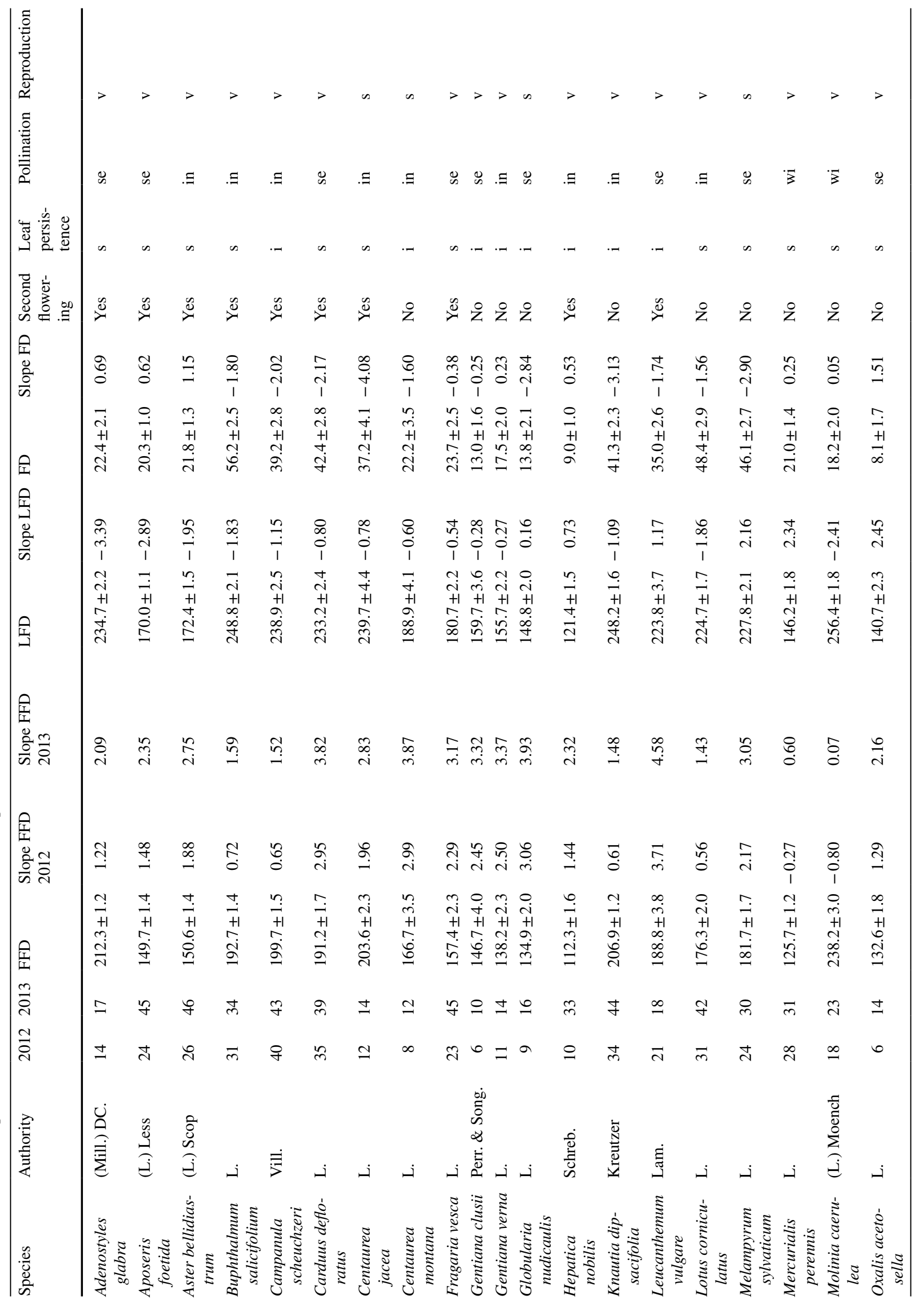




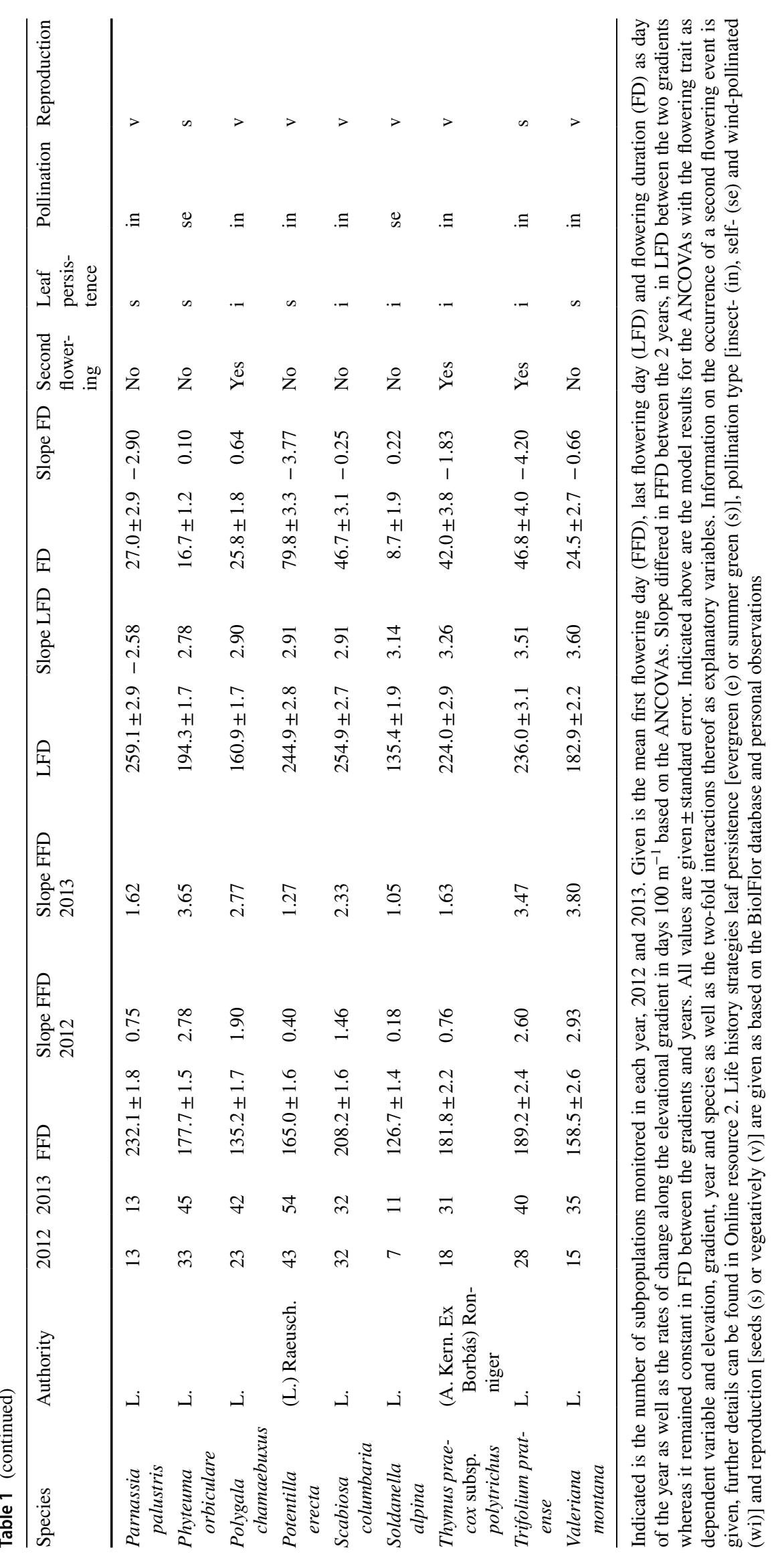


FFD and LFD were scaled to zero mean and unit variance prior to analysis to extract the relative impact of both parameters from the models' estimates. As before, models were simplified via backwards selection and model requirements were checked.

To investigate the effects of life-history strategies, i.e. leaf persistence, pollination syndrome and reproduction strategy on flowering phenology, we tested whether FFD, LFD and FD (calculated for each species, year and gradient) differed between evergreen and summer green species, between insect-, self- and wind-pollinated species and between species with generative and vegetative reproduction using ANOVAs, after checking that model requirements were met. For FFD we ran the analysis twice, once for the first flowering event and once for the second. In the case of LFD and FD we included both the values based on the first flowering event and the values which included a second flowering event as described above to see which impact these second flowering events had on the overall flower availability. To test for significant differences between the categories of the investigated life-history strategies, we used Tukey's HSD post hoc tests. Accordingly, we performed the same analyses using the slopes along the elevational gradient as the dependent variable to test the influence of life-history strategies on the response of flowering phenology. Again, this was done including the second flowering event as well.

All statistical analyses were computed in R 3.4.2 (R Core Team 2017). The results were graphically displayed using the package 'ggplot2' (Wickham 2009).

\section{Results}

\section{Changes in flowering patterns along the elevational gradient}

First flowering day changed with elevation and the intensity of this change was highly species-specific, differing between both years but in general FFD occurred earlier in lower elevations (Fig. 1a, Online resource 3, see Table 1 for mean values and Table 2 for statistical results). FFD was generally earlier in 2013 compared with 2012, and later on Kreuzeck than on Kramer. Hepatica nobilis was the first species to start flowering on day 95 in 2013, i.e. 5th of April at $800 \mathrm{~m}$ a.s.l. on Kramer, and Leucanthemum vulgare started to flower last, namely on day 279 in 2012, i.e. 6th of October on Kramer at $1500 \mathrm{~m}$ a.s.l.

LFD (Fig. 1b, Online resource 4, Table 1) showed a highly species-specific change along the elevational gradient (Table 2). Twelve species delayed LFD whereas others advanced LFD with increasing elevation. H. nobilis stopped flowering the earliest, namely on day 102 in 2013, i.e. 12th of April at 800 and at $950 \mathrm{~m}$ a.s.1. on Kramer whereas Carduus defloratus stopped flowering last, namely on day 311 in 2012 at $800 \mathrm{~m}$ a.s.l. on Kreuzeck, i.e. 7th of November.

Two-thirds of the species showed shorter FD with increasing elevation (Fig. 1c, Online resource 5, see Table 1 for mean values and Table 2 for statistical results). Overall, Trifolium pratense and $P$. erecta displayed the longest flowering duration with 140 days at $900 \mathrm{~m}$ a.s.1. on Kreuzeck and at $750 \mathrm{~m}$ a.s.1. on Kramer, both in 2013. O. acetosella only flowered for 8.2 days on average and in most cases less than a week, which is the shortest FD.

In total 13 species in 51 subpopulations displayed a second flowering event (see Online resource 2). Only in 11 subpopulations did second flowering last for longer than a week. We found that neither the timing of FFD, nor LFD, nor FD had any significant effect on the occurrence of a second flowering event. The beginning of the second flowering did not change with elevation (Table 2). The end of the second flowering event did not change with elevation and only depended on species and gradient, with Kreuzeck showing an earlier end of the second flowering phase than Kramer $\left(R^{2}=0.74, F_{13,37}=8.2, p<0.001\right)$. However, considering the combined flowering phenology data including the second flowering event showed that this was strongly affected by elevation (Table 2). On this combined dataset, the strongest intensity of change along the elevational gradient was also displayed by $C$. jacea, which showed an advance of 4.3 days $100 \mathrm{~m}^{-1}$ increase in elevation, whereas $A$. bellidiastrum showed a delay in LFD of 3.59 days $100 \mathrm{~m}^{-1}$.

The duration of the second flowering event was not influenced by gradient, elevation, year or species or the interactions thereof. When looking at the combined duration of both flowering events we found that elevation, gradient, species and year had a significant influence on FD (Table 2). The same species as above showed the longest flowering duration. Again, O. acetosella showed the strongest positive shift as it increased FD by 1.49 days $100 \mathrm{~m}^{-1}$ increase in elevation, while $T$. pratense displayed the strongest negative shift of 4.73 days $100 \mathrm{~m}^{-1}$.

\section{Differences in phenological response between early- and late-flowering species}

The timing of FFD significantly influenced the intensity of change of FFD along the elevational gradient: the earlier the flowering, the stronger the intensity of change along the elevational gradient, i.e. the more FFD was delayed with increasing elevation $\left(R^{2}=0.04, F_{1,111}=4.7, p<0.05\right.$; Fig. 2a).

There was a strong relationship between mean LFD and shifts in LFD along the elevational gradient. The strongest delays were found in species with earlier LFD $\left(R^{2}=0.40\right.$, $F_{1,111}=75.2, p<0.001$; Fig. $\left.2 b\right)$. The regression line 

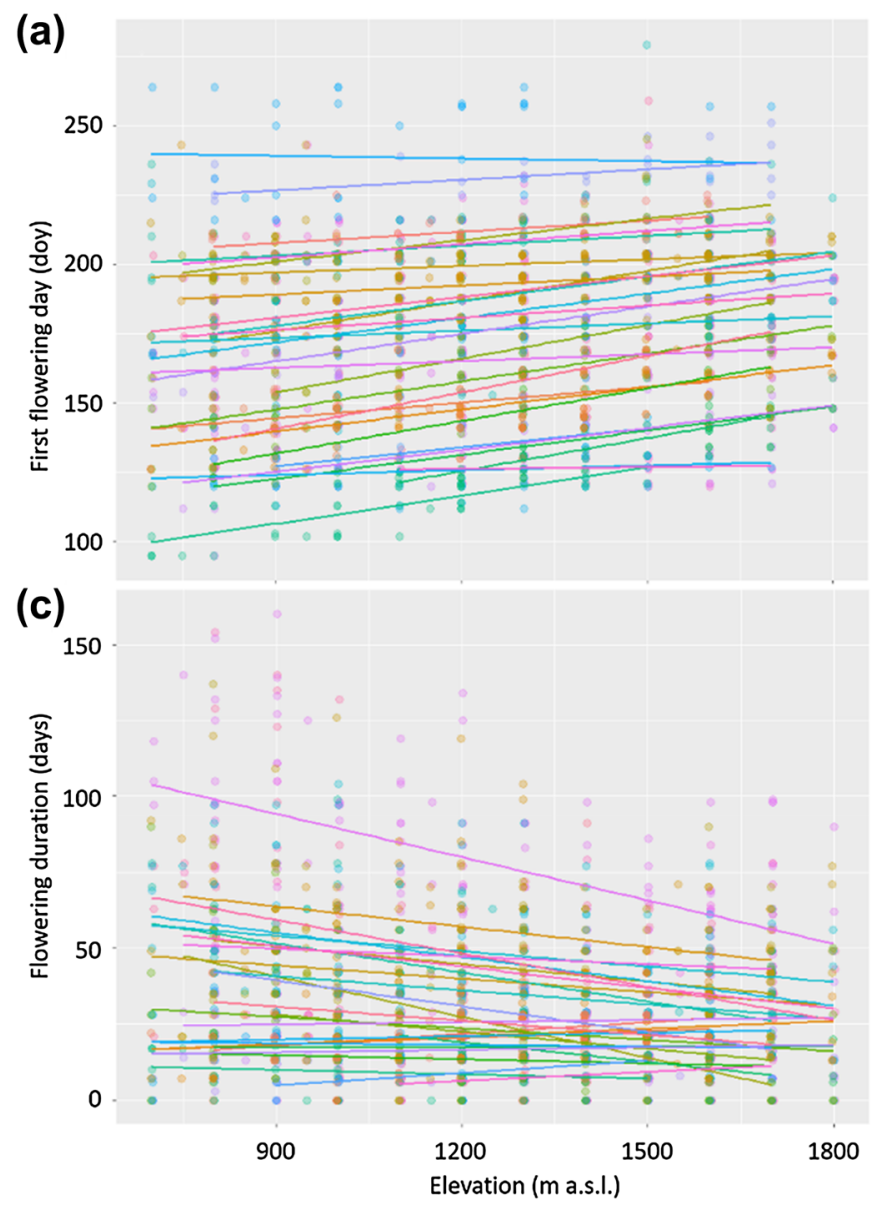

Fig. 1 Changes in flowering patterns along the elevational gradient. a Changes in first flowering day (FFD) along the elevational gradient, b changes in last flowering day (LFD) along the elevational gradient in day of the year (doy), c changes in flowering duration (FD) along

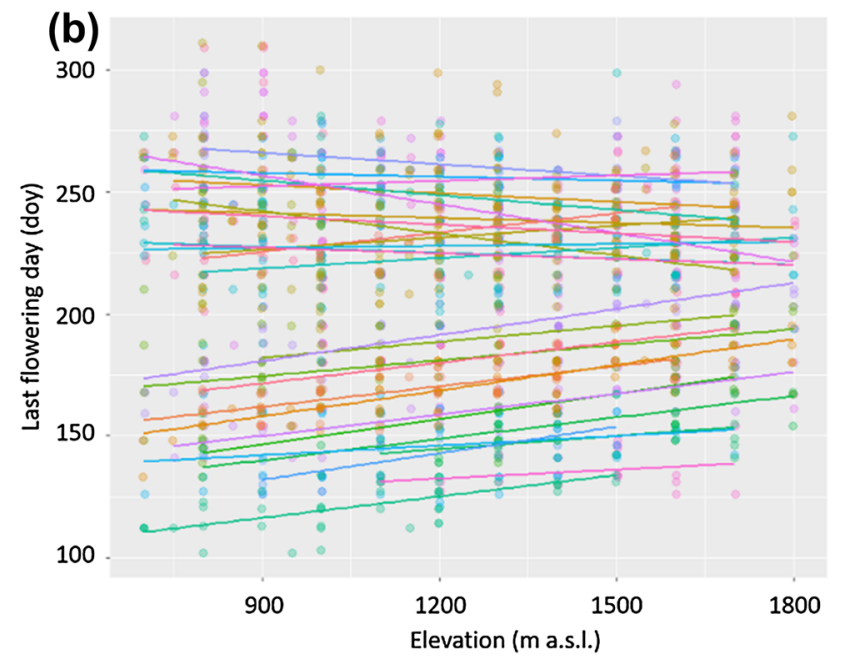

the elevational gradient. The colours represent species as explained in Figures S3-S5. Regression lines represent linear regression as based solely on elevational changes for simplicity reasons. Second flowering events are not included in the graph

Table 2 Results of the linear models describing changes of flowering penology with elevation (FFD, first flowering day; LFD, last flowering day; FD, flowering duration; all ex- and including second flowering events)

\begin{tabular}{|c|c|c|c|c|c|c|}
\hline & FFD & $\mathrm{FFD}_{\text {second }}$ & LFD & $\mathrm{LFD}_{\text {second }}$ & FD & $\mathrm{FD}_{\text {second }}$ \\
\hline Model results & $\begin{array}{l}R^{2}=0.90, \\
\quad F_{115,816}=61.7^{* * *}\end{array}$ & $\begin{array}{l}R^{2}=0.66 \\
\quad F_{12,38}=6.1^{* * * *}\end{array}$ & $\begin{array}{l}R^{2}=0.90 \\
\quad F_{115,814}=65.1 * * *\end{array}$ & $\begin{array}{l}R^{2}=0.85, \\
\quad F_{85,843}=55.9^{* * *}\end{array}$ & $\begin{array}{l}R^{2}=0.58, \\
\quad F_{87,840}=13.6^{* * *}\end{array}$ & $\begin{array}{l}R^{2}=0.59 \\
\quad F_{87,840}=13.8^{* * * *}\end{array}$ \\
\hline Elevation & $* * *$ & - & n.s. & $* *$ & $* * *$ & $* * *$ \\
\hline Species & $* * *$ & $* * *$ & $* * *$ & $* * *$ & $* * *$ & $* * *$ \\
\hline Year & n.s. & - & n.s. & n.s. & n.s. & n.s. \\
\hline Gradient & n.s. & - & $* *$ & n.s. & $*$ & $* *$ \\
\hline Elevation:species & $* * *$ & - & $* * *$ & $* * *$ & $* * *$ & $* * *$ \\
\hline Elevation:year & $* *$ & - & - & - & - & - \\
\hline Elevation:gradient & - & - & - & - & - & - \\
\hline Species:year & $* * *$ & - & $* * *$ & - & $*$ & $*$ \\
\hline Species:gradient & $* * *$ & - & $* * *$ & $* * *$ & - & - \\
\hline Gradient:year & - & - & - & - & - & - \\
\hline
\end{tabular}

Given are the explanatory variables and their significance in the minimum adequate models as well as the $R^{2}$ statistics and the $F$ statistics of the overall model $(* * * p<0.001, * * p<0.01, * p<0.05, n . s$. not significant, - not included in the final model) 
(a)
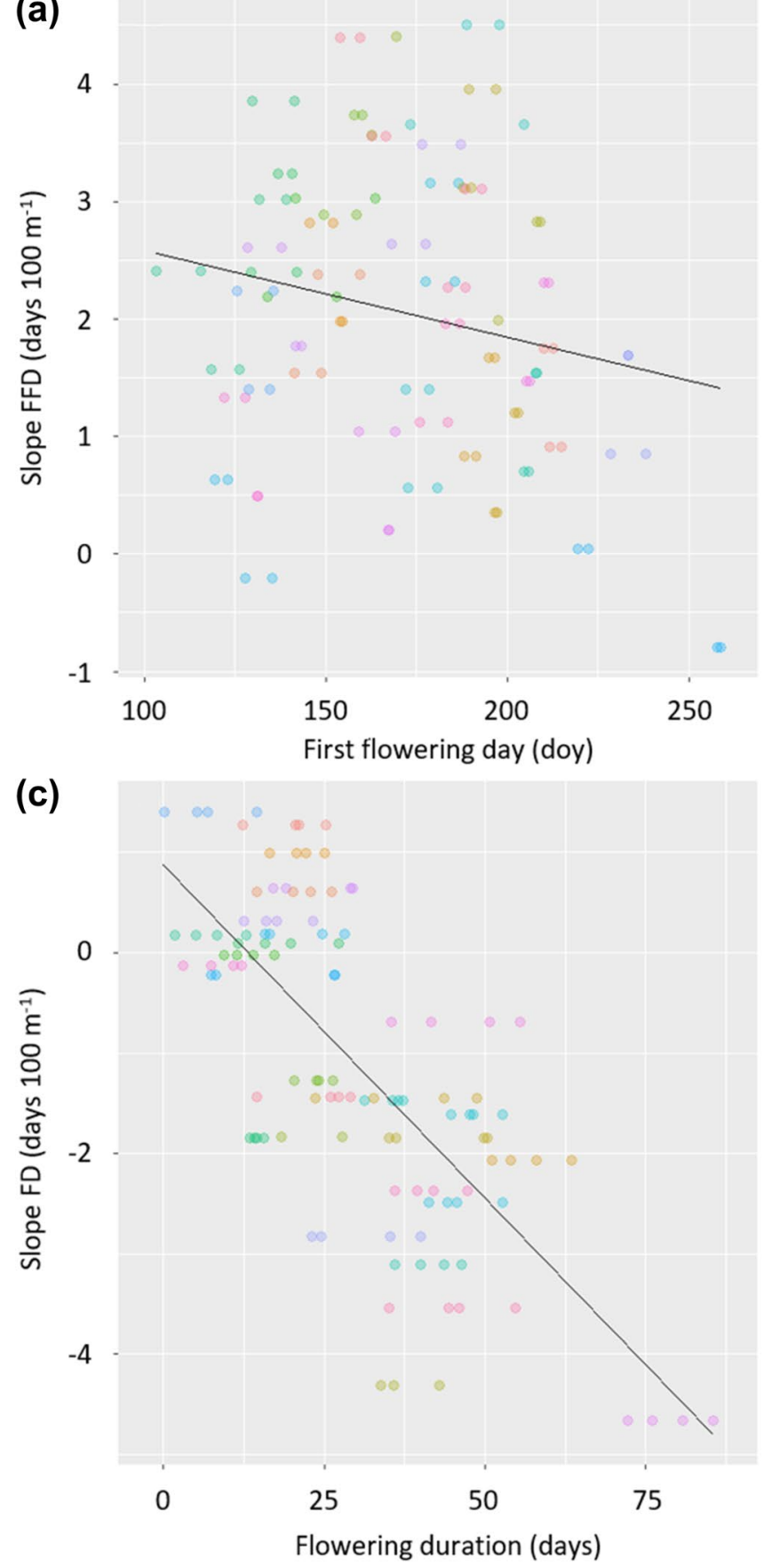

Fig. 2 Relationship between the timing of flowering event and shifts along the elevational gradient. Linear relationship between a first flowering day (FFD) and changes in FFD in days $100 \mathrm{~m}^{-1}$ increase in elevation, $\mathbf{b}$ last flowering day (LFD) and changes in LFD in days $100 \mathrm{~m}^{-1}$ increase in elevation and $\mathbf{c}$ flowering duration (FD) and

transects the $x$-axis indicating negative shifts at day 230 . When using the overall last flowering day for each population and looking at its relationship between that date and the slope along the elevational gradient we found a similar (b) 4

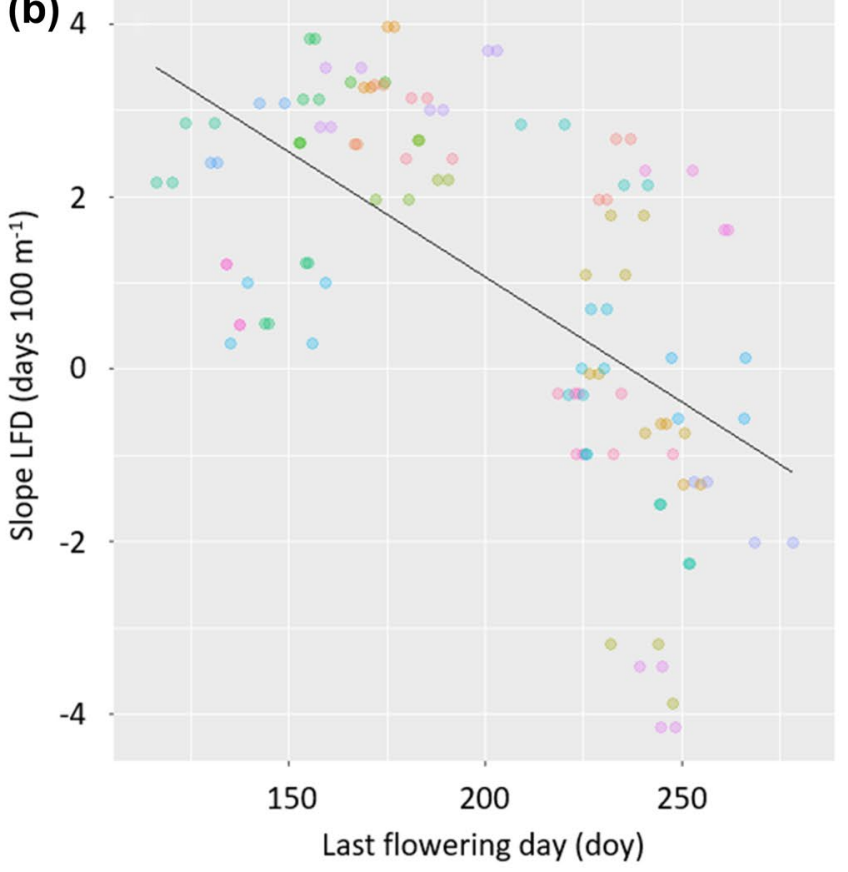

Last flowering day (doy) changes in FD in days $100 \mathrm{~m}^{-1}$ increase in elevation. Lines represent regression lines as based on ANCOVAs. The colours represent species as explained in Figures S3-S5. Second flowering events are not included in the graph

pattern $\left(R^{2}=0.34, F_{1,111}=56.0, p<0.001\right)$ with a transection of the $x$-axis on day 232 .

There was a pronounced negative relationship between FD and shifts in FD along the elevational gradient 
$\left(R^{2}=0.45, F_{1,111}=91.1, p<0.001\right.$; Fig. $\left.2 \mathrm{c}\right)$. Thus, longflowering species showed a pronounced decrease in flowering duration along the elevational gradient, whereas the opposite was true for short-flowering species. The regression line transects the $x$-axis indicating negative shifts at a duration of 25 days. When including the second flowering event, there was still a negative relationship between the duration of both flowering events and the slope of the duration along the elevational gradient $\left(R^{2}=0.44\right.$, $\left.F_{1,111}=88.6, p<0.001\right)$. However, the regression line already transects the $x$-axis at a duration of 12 days.

\section{Relationships between FFD, LFD and FD and the relative effects of changes in FFD and LFD on FD}

For most species, there was a positive relationship between FFD and LFD, i.e. the later the start, the later the end of flowering except in the case of Knautia dipsacifolia, Melampyrum sylvaticum, P. erecta, Lotus corniculatus, Thymus praecox and $T$. pratense. LFD was significantly influenced by FFD, gradient, species and the interactions FFD:gradient, FFD:species and gradient:species whereas year was not significant $\left(R^{2}=0.86, F_{86,1343}=97.6, p<0.001\right.$; Fig. 3a). Including the second flowering event showed that LFD was significantly influenced by FFD, gradient, species and
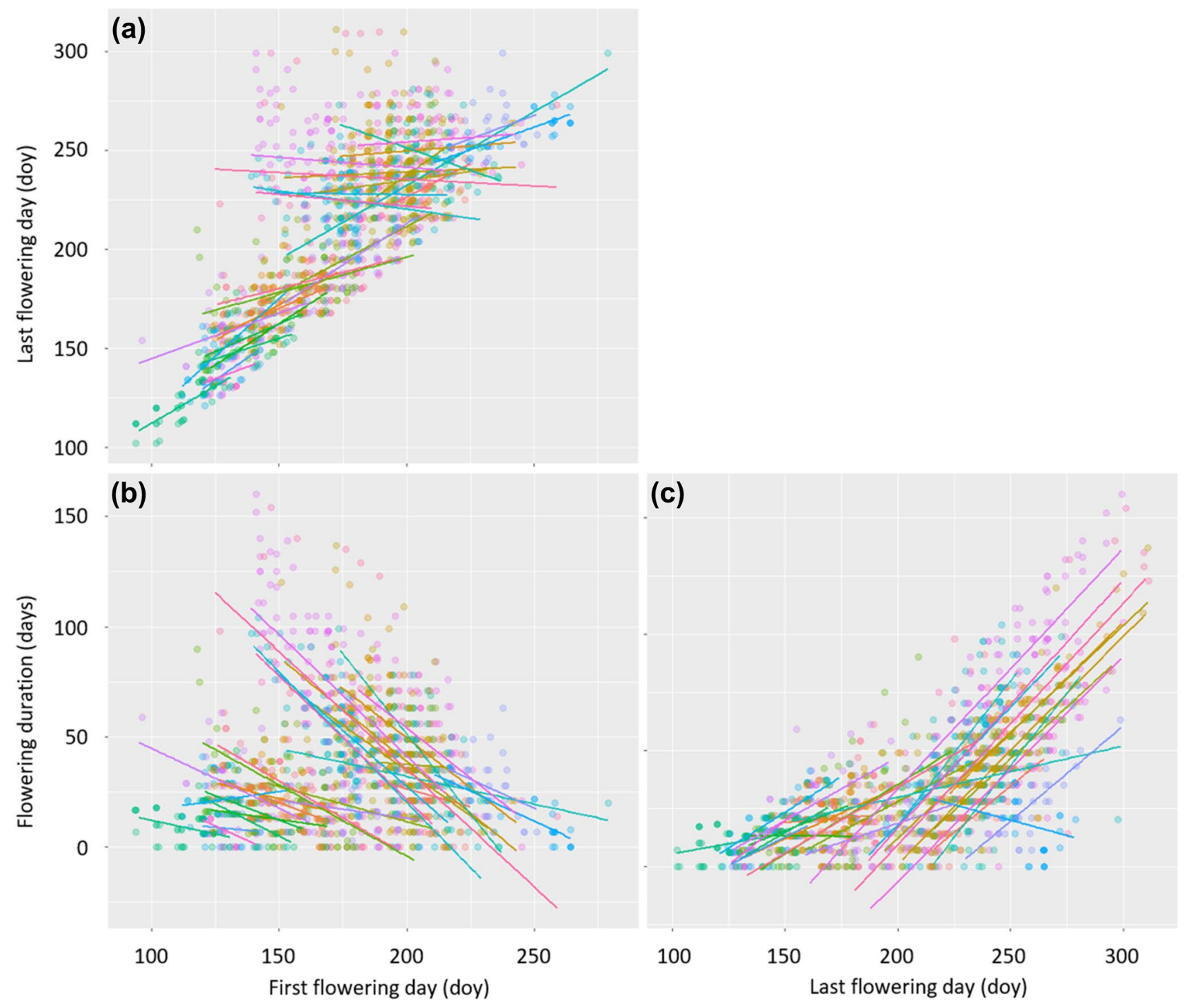

Fig. 3 Relationship between different events of flowering patterns. a Relationship between first and last flowering day, b between first flowering day and flowering duration and $\mathbf{c}$ between last flowering day and flowering duration. Given is the regression line for each species. The colours represent species as explained in Figures S3-S5. Second flowering events are not included in the graph 

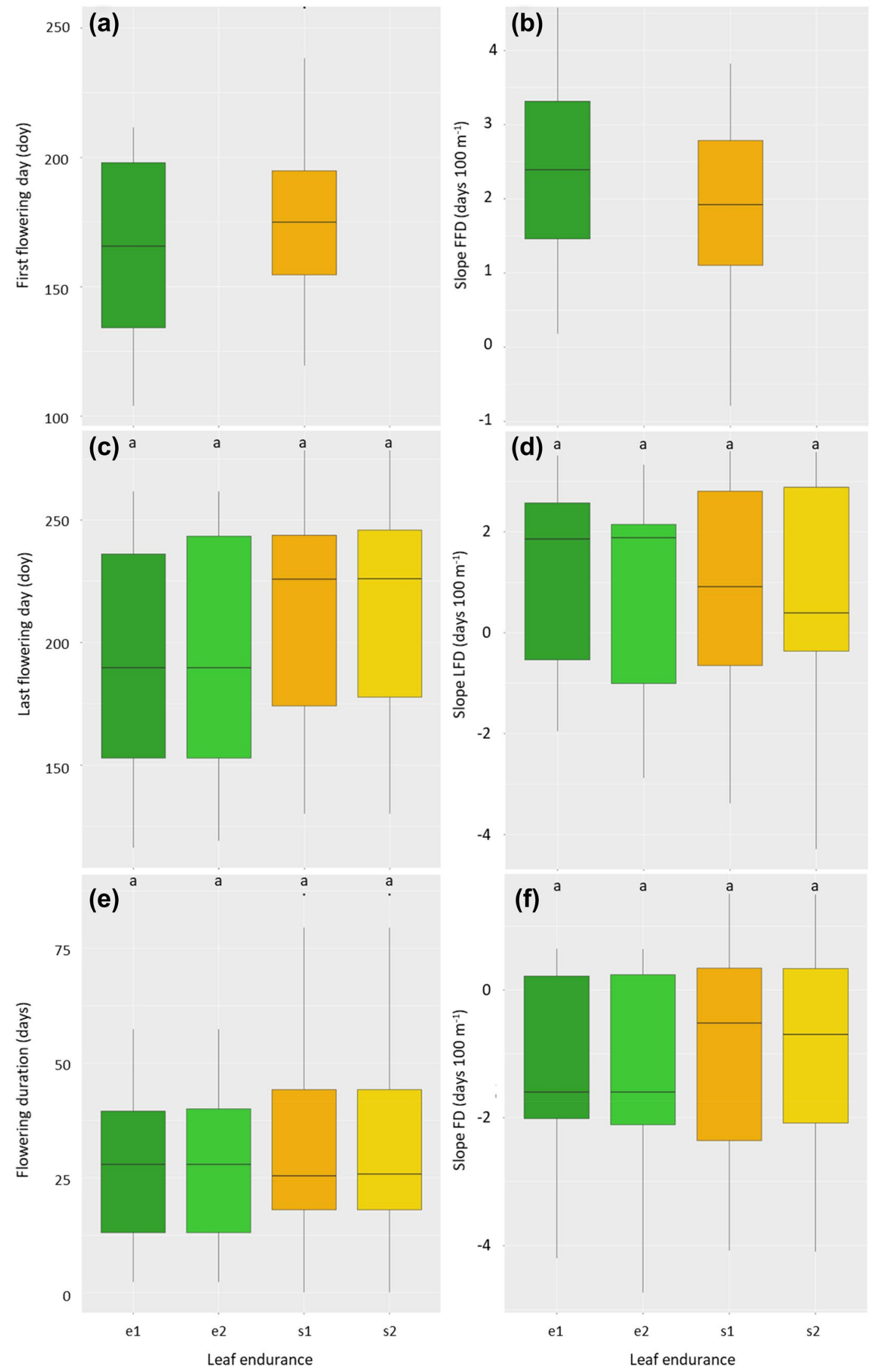
4Fig. 4 Flowering phenology on the left and panel and changes in flowering phenology on the right-hand panel as dependent on leaf persistence [evergreen (e, green) vs. summer green (s, yellow)]. a First flowering day (FFD), b shifts in FFD, $\mathbf{c}$ last flowering day (LFD) ex- (e1 and s1, respectively) and including second flowering events (e2 and s2), $\mathbf{d}$ shifts in LFD, all in day of the year (doy), e flowering duration (FD) and $\mathbf{f}$ shifts in FD, again without and with second flowering events and in days per $100 \mathrm{~m}^{-1}$. Darker colours are excluding second flowering; lighter colours are including it. Letters indicate significant differences based on Tukey's HSD post hoc test. Significance is at the $p<0.05$ level

the interactions FFD:gradient, FFD:species $\left(R^{2}=0.83\right.$, $\left.F_{59,1370}=113.0, p<0.001\right)$.

In general, there was a negative relationship between FFD and FD, i.e. populations which flowered earlier also tended to flower longer. The only species which showed opposing trends were $M$. perennis. FD was significantly influenced by FFD, species, gradient and the interactions FFD:gradient, FFD:species and gradient:species $\left(R^{2}=0.64, F_{86,1343}=28.2\right.$, $p<0.001$; Fig. 3b). Again, there were no significant differences between the 2 years. When the overall flowering duration was analysed, we found that FD was significantly influenced by FFD, species, gradient, year and the interactions FFD:gradient, FFD:species, gradient:species, FFD:year and species:year were significant $\left(R^{2}=0.66, F_{116,1313}=21.5\right.$, $p<0.001)$.

There was a positive relationship between LFD and FD, i.e. the longer the FD, the later a population stopped flowering. This was not only dependent on LFD but also on gradient, species, year and the interactions LFD:gradient and LFD:species as well as species:year $\left(R^{2}=0.80\right.$, $F_{88,1341}=59.5, p<0.001 ;$ Fig. $\left.3 \mathrm{c}\right)$. When adding the second flowering event, we found that FD was influenced by LFD, gradient, species, year and the interactions LFD:species as well as species:year $\left(R^{2}=0.76, F_{87,1342}=48.0, p<0.001\right)$.

The linear regression testing the influence of FFD and LFD on FD demonstrated that LFD had a slightly higher influence (estimate $=43.2 * * *)$ than FFD (estimate $\left.=-32.5^{* * *}\right)$ on FD $\left(R^{2}=1.0, F_{2,1427}=7.0 \mathrm{e}^{31}\right.$, $p<0.001)$. When including the second flowering event we could confirm this (estimate $=-28.3 * * *$ for FFD vs. $38.8^{* * *}$ for LFD, $\left.R^{2}=0.87, F_{2,1427}=4806, p<0.001\right)$.

\section{Influence of life-history strategies on patterns and shifts of flowering phenology}

The results showed that summer green species had later FFD and LFD than evergreen species, whereas FD did not differ between these strategies (Fig. 4; Table 3). The timing of the second flowering event was independent of leaf persistence. Including the second flowering event in the analysis did not change the overall patterns. There was a significant influence of leaf persistence on the shifts of FFD with evergreen species showing stronger positive shifts (Fig. 4b; Table 3), whereas evergreen and summer green species did not differ in their intensities of change of LFD and FD along the elevation gradient. When including the second flowering event, we found that there was again no significant difference between evergreen and summer green species concerning LFD and FD (Table 3).

FFD did not differ significantly between the three types of pollination. Insect-pollinated species had the latest LFD and differed significantly from self-pollinated species, with wind-pollinated species being in between (Table 3). FD was longer in insect-pollinated species than in wind- and selfpollinated species (Fig. 5e; Table 3). Again, including the second flowering event did not change the results. Changes in FFD along the elevational gradient were strongest in selfpollinated species and lowest in wind-pollinated species, where also negative values occurred. Insect-pollinated species showed an intermediate slope (Table 3). The intensity of change of LFD along the elevational gradient was highest in self-pollinated species, whereas there was no significant difference between insect- and wind-pollinated species (Table 3). The intensity of change of FD was significantly lower in insect-pollinated species than in self- and wind-pollinated species (Fig. 5f; Table 3). Second flowering events did not occur in wind-pollinated species.

The type of reproduction influenced flowering phenology. Species which mainly reproduce sexually via seeds showed no significant difference in FFD, LFD and FD from species which are able to spread vegetatively (Fig. 6; Table 3) and second flowering events did not change this pattern. However, the intensity of change of FFD differed between the different types of reproduction with species dispersing via seeds having larger changes than species which reproduce vegetatively (Fig. 6a; Table 3). The slope of LFD also changes significantly between different types of reproduction, with species with vegetative reproduction having a higher slope (Table 3). Here, including the second flowering event mattered, as the slope was slightly decreased compared with the first event only (Fig. 6d). The slope of FD was significantly higher in species able to disperse vegetatively than in species which propagate via seeds; second flowering events did not change the pattern (Fig. 6f; Table 3).

\section{Discussion}

This study clearly demonstrated that flowering patterns, i.e. FFD, LFD and FD changed significantly along elevational gradients with species-specific intensities. This was related to the life history strategies of the species, and there was a strong link between the different stages of flowering phenology. There was a delay in FFD and a decrease in flowering duration with increasing elevation for most of the 29 species 
Table 3 Results of the ANOVAs comparing first flowering day (FFD), last flowering day (LFD) and flowering duration (FD) as well as theirs slopes between different life history strategies namely leaf persistence, i.e. evergreen or summer green, pollination syndrome (insect- vs. self- or wind-pollination) or reproduction type (sexual vs. vegetative)

\begin{tabular}{lllllll}
\hline & FFD & Slope FFD & LFD & Slope LFD & FD & Slope FD \\
\hline Leaf persistence & $F_{1,111}=4.2^{*}$ & $F_{1,114}=6.5^{*}$ & $F_{3,222}=2.9^{*}$ & n.s. & n.s. & n.s. \\
Pollination & n.s. & $F_{2,113}=25.0^{* * *}$ & $F_{5,220}=4.1^{* *}$ & $F_{5,226}=6.6^{* * *}$ & $F_{5,220}=9.0^{* * *}$ & $F_{5,226}=6.1^{* * *}$ \\
Reproduction & n.s. & $F_{1,114}=14.6^{* * *}$ & n.s. & $F_{3,228}=7.2^{* * *}$ & n.s. & $F_{3,228}=24.3 * * *$ \\
\hline
\end{tabular}

studied, whereas LFD differed depending on the general timing of the phenological events of the species. Species which finished their flowering phenology early in the year delayed LFD along the elevational gradient, yet species which continued to flower longer showed hardly any changes along the elevational gradient. We found that the intensity of change of FFD, LFD and FD along the elevational gradient declined during the growth period and also changed from being positive to negative in the course of the year. Life history strategies related to leaf persistence, pollination and reproduction had significant effects on phenology and changes in phenology along the elevational gradient. In contrast to other studies, we also included the observations of second flowering events in our study and not only showed that these were rare and independent of elevation, but also that the overall results of our analysis hardly changed when second flowering events were included in the analyses.

The uniform trend of delaying FFD with increasing elevation and the stronger advance of FFD with increasing temperature in early-flowering compared with lateflowering species confirms the results of previous studies (Fitter and Fitter 2002; Menzel et al. 2006a; Miller-Rushing and Primack 2008). However, we could also show that the shift of LFD was highly dependent on the timing of LFD, as species which stop flowering late in the year showed an advance or no reaction along the elevational gradient. Species which displayed early LFD showed a shift to later days with increasing elevation while this pattern was reversed for species with late LFD (i.e. around day 230; Fig. 1b). This could be due to the fact that species which complete their reproduction early in the year respond more strongly to changes in temperature than species which reproduce later in the year. For species which extend their flowering phenology to later dates, cues such as photoperiod could be a stronger cue to stop flowering than for species which follow an early flowering strategy, which has been shown previously (Heide 1993; Häkkinen et al. 1998; Migliavacca et al. 2008; Migliavacca et al. 2011; Bucher et al. 2018). As it gets warmer, long-flowering species exhibit the strongest increase in FD and thus provide food for pollinator species for a longer period of time. The decrease in FD along the elevational gradient is also evidence for the countergradient variability hypothesis, which states that higher elevational species are
Fig. 5 Flowering phenology on the left and panel and changes in flowering phenology on the right-hand panel as dependent on pollination syndrome. a First flowering day (FFD), b shifts in FFD, c last flowering day (LFD) ex- (e1 and s1, respectively) and including second flowering events (e2 and s2), d shifts in LFD, all in day of the year (doy), e flowering duration (FD) and $\mathbf{f}$ shifts in FD, again without and with second flowering events and in days per $100 \mathrm{~m}^{-1}$. Colours represent the type of pollination: on type of pollination, i.e. insect- (in, pink), self- (se, green) and wind-pollinated (wi, blue). Darker colours are excluding second flowering; lighter colours are including it. Letters indicate significant differences based on Tukey's HSD post hoc test. Significance is at the $p<0.05$ level

able to complete their life-cycle in a shorter period of time than species from a lower elevation (Conover and Schultz 1995; Körner 2003). However, Petanidou et al. (1995) demonstrated for Gentiana pneumonanthe L. that female fecundity is reduced later in the season, probably due to nutrient limitations, thus extending the flowering duration might not be enough to counterbalance the loss of pollination service early in the season. In contrast to our findings, Trunschke and Stöcklin (2017) demonstrated an increase in FD. However, this was within individuals and not populations with increasing elevation in the Central Swiss Alps and linked this to limited pollination success; they also demonstrated a higher plasticity of FD of plants originating from high elevations (2600 $\mathrm{m}$ a.s.l.) compared with plants from low elevations (1600 m a.s.1.). However, the uppermost limit of our research was $1800 \mathrm{~m}$ a.s.l., so the differing results may be due to the fact that the availability of pollinators might show a non-linear distribution along elevational gradients, i.e. showing a decrease again in alpine environments above the treeline. The strong differences between early- and lateflowering species concerning the link between different flowering stages also emphasises the fact that it is important not only to focus on FFD but also to take LFD, and thus FD into consideration when looking at flowering phenology from an ecological point of view as the time available for possible pollination and fertilisation.

There were differences in the response of flowering phenology along the elevational gradient between the 2 years in FFD and between the two gradients in LFD whereas the shifts were constant in FD. FFD was earlier in 2013 than in 2012 which can be explained by the less severe winter conditions (Online resource 1). However, the rate of change with 


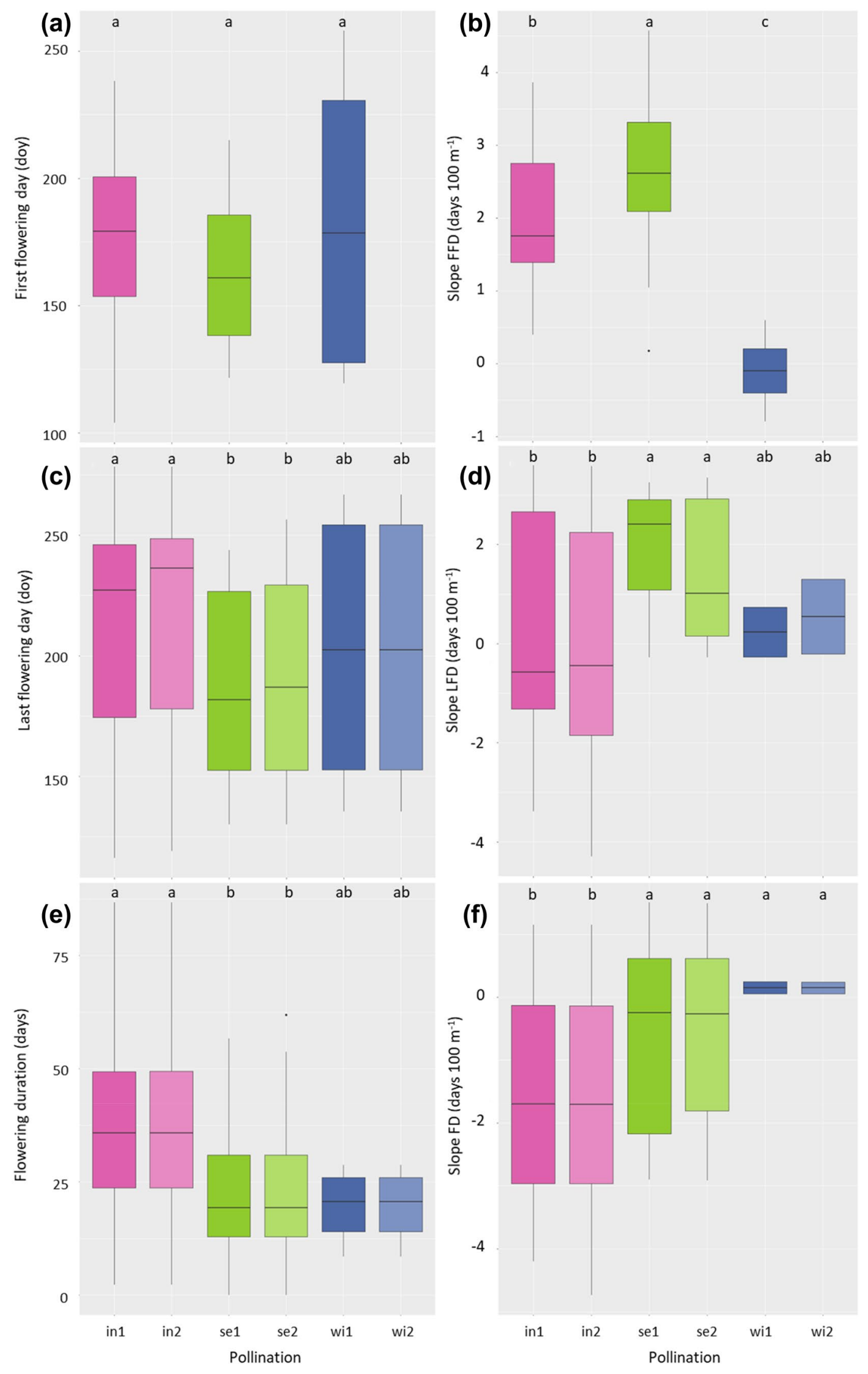




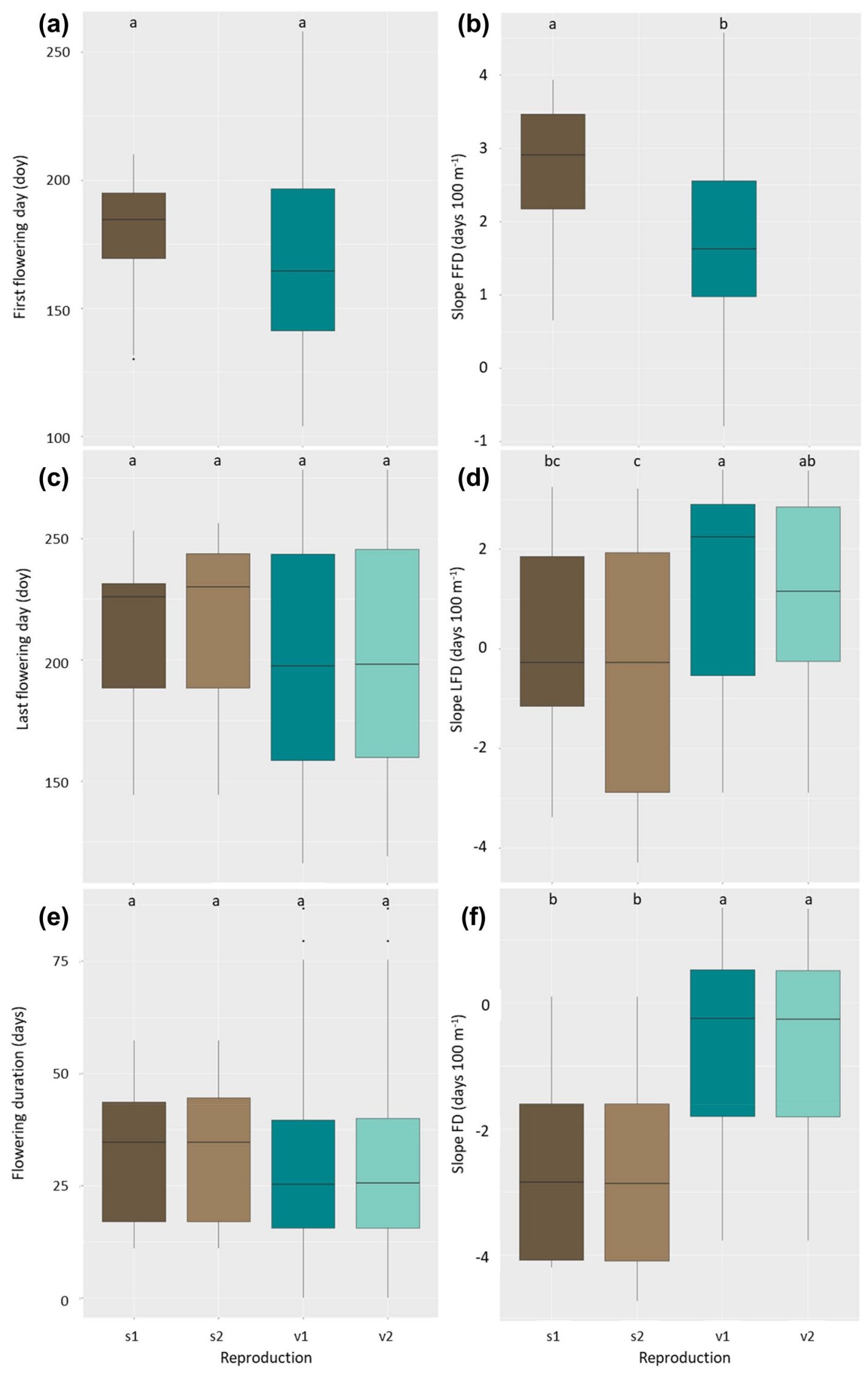


4Fig. 6 Flowering phenology on the left and panel and changes in flowering phenology on the right-hand panel as dependent on reproduction. This was done for a first flowering day (FFD), b shifts in FFD, c last flowering day (LFD) ex- (s1 and v1, respectively) and including second flowering events ( $\mathrm{s} 2$ and v2), d shifts in LFD, all in day of the year (doy), e flowering duration (FD) and $\mathbf{f}$ shifts in FD, again without and with second flowering events and in days per $100 \mathrm{~m}^{-1}$. Species which reproduce via seeds (s) are displayed in brown, species which are able to spread vegetatively (v) in cyan. Darker colours are excluding second flowering; lighter colours are including it. Letters indicate significant differences based on Tukey's HSD post hoc test. Significance is at the $p<0.05$ level

elevation was in general higher in all species in 2013, which might be due to the fact that the winter and thus frost events persisted for much longer and spring began later in 2013. Daily maximum temperatures did not differ that strongly between the two gradients, but the minimum temperatures differed greatly, especially on the Kramer gradient which could have had a big impact for the plants in determining LFD. Other studies detected regional differences in FFD between different sites, which might be due to adaptation by local species (Ziello et al. 2009; Cornelius et al. 2013). Common garden experiments demonstrated that phenological phases were advanced but shortened at lower elevational sites (Gugger et al. 2015). Within congeneric species pairs, plants from lower elevations were in general more plastic in their response which might be due to the strong effect of late frost which imposed a strong abiotic filter especially at higher elevations (Gugger et al. 2015; Schmid et al. 2017). Nevertheless, it is interesting to see that FD, being the phase which is most influential for pollination success and the provision of food for pollinating insects, is the most conservative of the three phenological events and only changed with elevation, i.e. with temperature. It was not influenced by the temperature difference between the two gradients as Kreuzeck tended to be colder than Kramer and the temperature differed between the 2 years (Bucher et al. 2018; Online resource 1).

The initiation of a second flowering event was rare; in total, only 13 species displayed such a second flowering event, and for five of them it only occurred once. Moreover, not a single subpopulation flowered twice in 2012 and in 2013, which suggests that this is not a genetic predisposition and does not serve as a general strategy to prolong FD after the end of the first flowering phase. In addition, these second flowering events were very short in most subpopulations, much shorter than the first flowering phase. Thus, they are a minimal investment by the plant and not the same as a full flowering period. Interestingly, even though the timing of FFD, LFD and FD of the second flowering event was not influenced by elevation, it affected the overall flowering patterns when including them in the analyses and made slopes along the elevational gradient steeper. The second flowering event ended earlier on Kreuzeck gradient which is the colder of the two mountains, a pattern which could also be observed in the first flowering event. However, the lack of the relationship between second flowering event and elevation can also be inferred by the very low number of instances when a distinct second flowering event was observed. The trigger of a second flowering event seems thus not to be solely temperature but might rather also be induced by an unsuccessful pollination during the first phase. On the other hand, it could be induced by a surplus in available resources or a saving of resources over several years, which enable the plant to invest in a second flowering event in 1 year and thereby increase the number of viable seeds. Including second flowering events and thus lengthening the observation period by several weeks even after LFD seems to be very important if not only flowering phenology is studied but also reproduction success which would probably explain the occurrence of second flowering events.

We found that the different events of flowering phenology, i.e. FFD, LFD and FD are interconnected: for most species, we found that when FFD was delayed, there was also a delay in LFD especially in species which flowered early in the year; and when LFD was delayed, FD was prolonged mainly in later flowering species. However, when looking at the species-specific results we found a negative relationship between FFD and FD, meaning that if FFD was delayed, FD became shorter, thus a delay in FFD due to unfavourable climate conditions leads to a shorter flowering which was more pronounced in late-flowering species. Thus early-flowering species shifted their phenology, which bears the mismatch with pollinators (Rathcke and Lacey 1985), whereas later flowering species extended the flowering phenology with warmer climate and thus might be able to benefit more from changing climate conditions. This might also be due to the fact that predictable frost events which occur early in the season might have a limiting effect on the plasticity of FFD (Schmid et al. 2017). In general, species advance FFD with warmer temperature as a result of climate change (Menzel et al. 2006a; Bock et al. 2014; Bucher et al. 2018; König et al. 2018) and a prolonged FD increases a plant species' opportunity for pollination, thereby increasing plant performance (Rathcke and Lacey 1985; Menzel et al. 2006b; Bock et al. 2014). Interestingly, it is neither the first nor the last flowering species which display the longest FD, but the species which flower during mid-season. In sub-Mediterranean mountain grasslands, the dominant species flower in the middle of the growing season when there is minimal stress and a long time for seed maturation (Catorci et al. 2012) which can also be seen in our data (analysis not shown), thus this niche seems to be the most favourable. There was no relationship between the timing of the first flowering event and the second, so starting and finishing the first flowering early in the year does not necessarily allow for more time 
to induce a second flowering event and thus, increase the chance of pollination.

Life history strategies explained both patterns and shifts in flowering phenology along the elevational gradient. Leaf persistence influenced the timing of phenology as evergreen species tended to have earlier FFD and LFD compared with summer green species, yet the shifts along the elevational gradient did not differ between the two types, only in FFD. In a temperate environment with cold winters, plants with evergreen leaves which are able to photosynthesise immediately after snowmelt without the necessity of using energy reserves for the construction of new leaves should have a developmental head start in flowering phenology. Evergreen species are also more frost resistant than summer green species, which makes them less endangered by late frost events. There seems to be the tendency that evergreen species extend FD more than summer green species, yet this is not significant and should be studied using a bigger dataset. LFD and FD were mainly influenced by the type of pollination as insect-pollinated species start to flower later in the season yet display longer FD. This confirms studies from Rathcke and Lacey (1985), who found that outcrossing species flower longer than self-pollinated species, yet it is not in line with Molau (1993) who documented higher outbreeding rates in early flowering species in tundra ecosystems. This is most probably due to temperature-dependent insect activity and also neatly matches the co-evolution and symbiosis between flowering plants and pollinators which depend on the plants as their main source of nutrition or might be linked to pollinator availability as suggested by Trunschke and Stöcklin (2017). Nevertheless, self-pollinated species showed the highest intensity of change of FFD and LFD along the elevational gradient, whereas insect-pollinated species showed a more negative slope of FD, thus being the most efficient in expanding FD with warmer temperatures. Wind-pollinated species did not shift their flowering phenology along the elevational gradient much at all, which might indicate that they are unaffected by temperature and instead respond to other triggers such as precipitation or wind to trigger the opening of the flowers or simply respond to photoperiod or also to any kind of disturbance. Species which propagate via seeds showed no difference in FFD, LFD and FD compared with species, which may propagate vegetatively. Still, species which propagate via seeds displayed steepest slopes in FFD along the elevational gradient, but almost none in LFD which lead to a higher increase in FD. Species which reproduce vegetatively rather shifted the flowering phenology towards earlier dates with warmer temperature than extending FD. This might be either due to the fact that sexual reproduction is favourable during changing abiotic conditions or due to the temperature dependence of seed formation. There were no differences between the timing of a second flowering event and leaf persistence, pollination syndrome or reproduction. However, it was interesting to note that no wind-pollinated species showed a second flowering event, which might be due to higher fertilisation success rates of wind-pollination.

\section{Conclusion}

Our study demonstrates that flowering phenology varies with changing abiotic conditions but that these changes are species-specific as well as dependent on life-history strategies and the overall timing of flowering phenology. A second flowering event seems not to be related to abiotic conditions but most likely to the pollination success of the first flowering event. Species-specific shifts in flowering phenology can alter co-flowering patterns (species which are flowering at the same time) within a community, and redistribute floral abundances across seasons (CaraDonna et al. 2014). We found differences of flowering phenology between different life-history strategies. Understanding species-specific flowering patterns in relation to changing abiotic conditions is, therefore, crucial to predicting species performance and patterns of coexistence with a changing climate. The ability to predict these will improve our understanding and forecasting of future biodiversity, ecosystem functions and ecosystems services.

Acknowledgements We would like to thank the members of the former Institute of Systematic Botany of the Friedrich Schiller University Jena for practical assistance, fruitful discussions and support, most of all Birgit Lang, Patrizia König and Emma Jardine. The authors would like to thank Christina Schuster, Annette Menzel and Benjamin Curtis for help and support. Additionally, we would like to thank two anonymous reviewers as well as Jürg Stöcklin for their thoughtful comments which helped to improve this manuscript. We also thank the Eliteförderung des Landes Bayern for provision of a scholarship (granted to SFB) and the Universities of Regensburg and Jena for financial support. We also thank the Bavarian State Forest Enterprise and the district government of upper Bavaria. Open Access funding was provided by Projekt DEAL.

Author contributions CR and SFB designed the study, SFB collected and analysed the data. Both authors contributed critically to the drafts and gave final approval for publication.

Funding This study was partially funded via a scholarship from the Eliteförderung des Landes Bayern granted to SFB.

Data accessibility statement The data will be made available on TRY database (http://www.try-db.org).

\section{Compliance with ethical standards}

Conflict of interest The authors declare that they have no conflict of interest. 
Open Access This article is licensed under a Creative Commons Attribution 4.0 International License, which permits use, sharing, adaptation, distribution and reproduction in any medium or format, as long as you give appropriate credit to the original author(s) and the source, provide a link to the Creative Commons licence, and indicate if changes were made. The images or other third party material in this article are included in the article's Creative Commons licence, unless indicated otherwise in a credit line to the material. If material is not included in the article's Creative Commons licence and your intended use is not permitted by statutory regulation or exceeds the permitted use, you will need to obtain permission directly from the copyright holder. To view a copy of this licence, visit http://creativecommons.org/licenses/by/4.0/.

\section{References}

Bock A, Sparks TH, Estrella N, Jee N, Casebow A, Schunk C et al (2014) Changes in first flowering dates and flowering duration of 232 plant species on the island of Guernsey. Glob Chang Biol 20:3508-3519

Bucher SF, König P, Menzel A, Migliavacca M, Ewald J, Römermann C (2018) Traits and climate are associated with first flowering day in herbaceous species along elevational gradients. Ecol Evol $8: 1147-1158$

CaraDonna PJ, Iler A, Inouye DW (2014) Shifts in flowering phenology reshape a subalpine plant community. Proc Natl Acad Sci USA 111:4916-4921

Catorci A, Carotenuto L, Gatti R (2012) Flowering patterns in subMediterranean grasslands: a functional approach. Plant Ecol Evol 145:165-175

Conover DO, Schultz ET (1995) Phenotypic similarity and the evolutionary significance of countergradient variation. Trends Ecol Evol 10:248-252

Cornelius C, Estrella N, Franz H, Menzel A (2013) Linking altitudinal gradients and temperature responses of plant phenology in the Bavarian Alps. Plant Biol 15:57-69

Crawley MJ (2012) The R book. Wiley, New York

Dunne JA, Harte J, Taylor KJ (2003) Subalpine meadow flowering phenology responses to climate change: integrating experimental and gradient methods. Ecol Monogr 73:69-86

Fitter A, Fitter R (2002) Rapid changes in flowering time in British plants. Science 296:1689-1691

Fitter A, Fitter R, Harris I, Williamson M (1995) Relationships between first flowering date and temperature in the flora of a locality in central England. Funct Ecol 9:55-60

Forrest J, Miller-Rushing AJ (2010) Toward a synthetic understanding of the role of phenology in ecology and evolution. Philos Trans R Soc B 365:3101-3112

Gugger S, Kesselring H, Stöcklin J, Hamann E (2015) Lower plasticity exhibited by high- versus mid-elevation species in their phenological responses to manipulated temperature and drought. Ann Bot 116:953-962

Häkkinen R, Linkosalo T, Hari P (1998) Effects of dormancy and environmental factors on timing of bud burst in Betula pendula. Tree Physiol 18:707-712

Heide O (1993) Daylength and thermal time responses of budburst during dormancy release in some northern deciduous trees. Physiol Plant 88:531-540

Hovenden MJ, Wills KE, Vander Schoor JK, Williams AL, Newton PC (2008) Flowering phenology in a species-rich temperate grassland is sensitive to warming but not elevated $\mathrm{CO}_{2}$. New Phytol 178:815-822

König P, Tautenhahn S, Cornelissen JHC, Kattge J, Bönisch G, Römermann C (2018) Advances in flowering phenology across the northern hemisphere are explained by functional traits. Glob Ecol Biogeogr 27:310-321

Körner C (2003) Alpine plant life: functional plant ecology of high mountain ecosystems; with 47 tables. Springer, Berlin

Körner C (2007) The use of 'altitude'in ecological research. Trends Ecol Evol 22:569-574

Kühn I, Durka W, Klotz S (2004) BiolFlor: a new plant-trait database as a tool for plant invasion ecology. Divers Distrib 10:363-365

Memmott J, Craze PG, Waser NM, Price MV (2007) Global warming and the disruption of plant-pollinator interactions. Ecol Lett 10:710-717

Menzel A, Sparks TH, Estrella N, Koch E, Aasa A, Ahas R et al (2006a) European phenological response to climate change matches the warming pattern. Glob Chang Biol 12:1969-1976

Menzel A, von Vopelius J, Estrella N, Schleip C, Dose V (2006b) Farmers' annual activities are not tracking the speed of climate change. Clim Res 32:201-207

Migliavacca M, Cremonese E, Colombo R, Busetto L, Galvagno M, Ganis L et al (2008) European larch phenology in the Alps: can we grasp the role of ecological factors by combining field observations and inverse modelling? Int J Biometeorol 52:587-605

Migliavacca M, Galvagno M, Cremonese E, Rossini M, Meroni M, Sonnentag $\mathrm{O}$ et al (2011) Using digital repeat photography and eddy covariance data to model grassland phenology and photosynthetic $\mathrm{CO}_{2}$ uptake. Agric For Meteorol 151:1325-1337

Miller-Rushing AJ, Primack RB (2008) Global warming and flowering times in Thoreau's Concord: a community perspective. Ecology 89:332-341

Miller-Rushing AJ, Katsuki T, Primack RB, Ishii Y, Lee SD, Higuchi H (2007) Impact of global warming on a group of related species and their hybrids: cherry tree (Rosaceae) flowering at Mt. Takao, Japan. Am J Bot 94:1470-1478

Molau U (1993) Relationships between flowering phenology and life history strategies in tundra plants. Arct Alp Res 25:391-402

Ollerton J, Lack A (1998) Relationships between flowering phenology, plant size and reproductive success in shape Lotus corniculatus (Fabaceae). Plant Ecol 139:35-47

Parmesan C (2007) Influences of species, latitudes and methodologies on estimates of phenological response to global warming. Glob Chang Biol 13:1860-1872

Petanidou T, Nijs JCM, Oostermeijer JGB, Ellis-Adam AC (1995) Pollination ecology and patch-dependent reproductive success of the rare perennial Gentiana pneumonanthe L. New Phytol 129:155-163

Petanidou T, Kallimanis AS, Sgardelis SP, Mazaris AD, Pantis JD, Waser NM (2014) Variable flowering phenology and pollinator use in a community suggest future phenological mismatch. Acta Oecol 59:104-111

R Core Team (2017) R: a language and environment for statistical computing. R Foundation for Statistical Computing Vienna, Austria

Rathcke B, Lacey EP (1985) Phenological patterns of terrestrial plants. Annu Rev Ecol Syst 16:179-214

Schmid SF, Stöcklin J, Hamann E, Kesselring H (2017) High-elevation plants have reduced plasticity in flowering time in response to warming compared to low-elevation congeners. Basic Appl Ecol 21:1-12

Schuster C, Estrella N, Menzel A (2014) Shifting and extension of phenological periods with increasing temperature along elevational transects in southern Bavaria. Plant Biol 16:332-344

Sherry RA, Zhou X, Gu S, Arnone JA, Schimel DS, Verburg PS et al (2007) Divergence of reproductive phenology under climate warming. Proc Natl Acad Sci USA 104:198-202

Trunschke J, Stöcklin J (2017) Plasticity of flower longevity in alpine plants is increased in populations from high elevation compared to low elevation populations. Alp Bot 127:41-51 
Visser ME, Both C (2005) Shifts in phenology due to global climate change: the need for a yardstick. Philos Trans R Soc B 272:2561-2569

Vitasse Y, Porté AJ, Kremer A, Michalet R, Delzon S (2009) Responses of canopy duration to temperature changes in four temperate tree species: relative contributions of spring and autumn leaf phenology. Oecologia 161:187-198

Waser NM, Real LA (1979) Effective mutualism between sequentially flowering plant species. Nature 281:670

Wickham H (2009) Ggplot2: elegant graphics for data analysis. Springer Science and Business Media, New York
Wolkovich EM, Cleland EE (2011) The phenology of plant invasions: a community ecology perspective. Front Ecol Environ 9:287-294

Ziello C, Estrella N, Kostova M, Koch E, Menzel A (2009) Influence of altitude on phenology of selected plant species in the Alpine region (1971-2000). Clim Res 39:227-234

Publisher's Note Springer Nature remains neutral with regard to jurisdictional claims in published maps and institutional affiliations. 